and high latitudes. Although Bateman et al. suggest that biogenic organic aerosols with a range of compositions change from solid to liquid when approximately one-quarter of the particle volume is water, this relationship will need to be verified for aerosols formed from other organic precursors under a greater variety of conditions before it is adopted in models. Furthermore, although the study sampled some air affected by urban emissions, the effect on organic phase was inconclusive. The emphasis of the study was on clean conditions in which particles were entirely secondary organic matter. Since aerosols influenced by urban, marine, soil and biomass-burning emissions can contain inorganic salts as well as soot and soil dust, studies of the effects of these components on particle phase are necessary. And even when a particle is liquid, it may be composed of separate organic and aqueous phases with very different chemical and physical properties that can affect its growth, chemistry and radiative effects.

Bateman et al. ${ }^{1}$ highlight the biomedependency and importance of relative humidity in determining the physical state of organic aerosols. Improving our understanding of the geographically variable and complex environmental controls over aerosol phase state will be essential for predicting how secondary organic aerosols form and for evaluating their impacts on climate.
Paul J. Ziemann is in the Department of Chemistry and Biochemistry and at the Cooperative Institute for Research in Environmental Sciences at the University of Colorado at Boulder, 216 UCB CIRES, Boulder, Colorado 80309, USA.

e-mail:paul.ziemann@colorado.edu

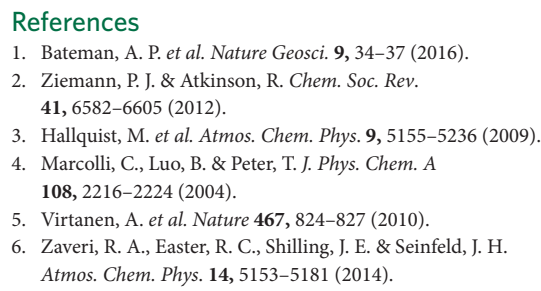

Published online: 7 December 2015

\title{
PALAEOECOLOGY
}

\section{The importance of herbivores}

Tens of thousands of years ago, massive herbivores - and the large predators that fed on them - roamed all the continents except for Antarctica. Following the end of the glaciation and the intensification of human hunting and landscape disturbance, Ice Age herbivores like the iconic mastodon and woolly rhinoceros died out across Europe, North and South America and parts of Asia. Only in Africa did most megafauna persist, with elephants, giraffes and smaller herbivores like oryx, gazelles and okapi (pictured) still roaming - and eating - across much of the continent today.

Across Africa, the herbivores are adapted to take advantage of the wide range of food types and seasonal patterns available. But the activities of these animals also shape their environment. In Australia, it is thought that the extinction of large browsing animals some 40,000 years ago allowed woody vegetation to expand, in turn making the landscape more prone to burning (R. A. Lopes dos Santos et al., Nature Geosci. 6, 627-631; 2013). By extension, the patterns of vegetation - the biome as well as the frequency of fire - the pyrome - in Africa are shaped to some extent by the herbivores that live there. Of course, with ongoing and intensifying hunting and landscape modification, the distributions of animals that established today's biomes may be very different to the distributions we see today.

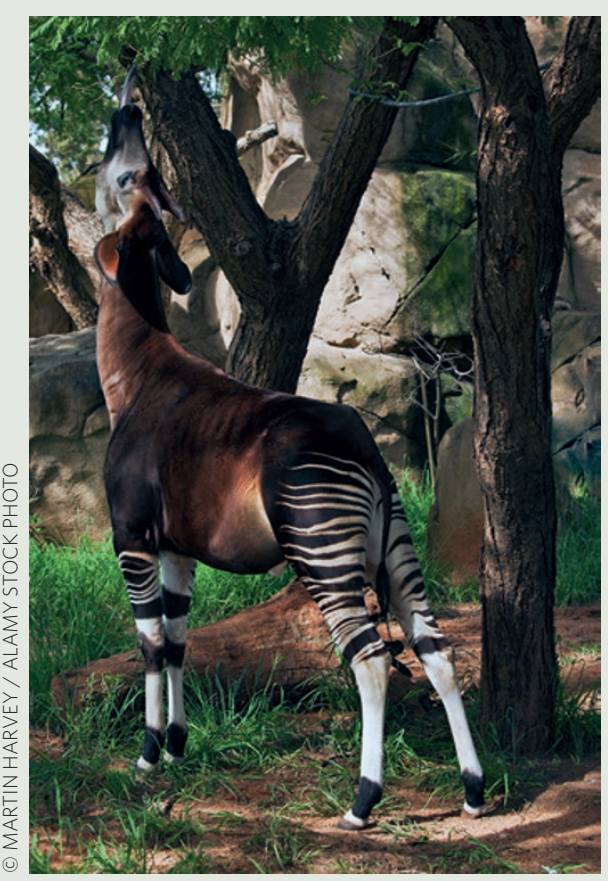

Gareth P. Hempson and colleagues therefore reconstructed the distribution and activities of herbivores across subSaharan Africa 1,000 years ago using statistical models and census data (Science 350, 1056-1061; 2015). Based on this reconstruction, they narrow down and group the various eating styles of the African herbivores - such as nonsocial browsers and water-dependent grazers. From this they identify four distinct patterns of herbivory, which they term herbivomes.

The herbivomes broadly correlate with some environmental parameters, such as mean annual rainfall and soil fertility. Intriguingly, they also seem to explain regions where environmental parameters and vegetation type do not correlate. For instance, the 'high VALS herbivome' (high variety and abundance of larger species) occurs in regions where the climate could support closed canopy forests, but tree cover is relatively limited. The high VALS herbivome features a high proportion of browsers, who feed on woody vegetation. Thus the researchers suggest that the herbivome is an important control on the type and structure of vegetation cover.

This census of pre-industrial herbivory has implications for conservation and sustainable land use in Africa. Certainly, both loss of large herbivores through hunting or loss of habitat, and reintroduction and rewilding of other herbivores have the potential to shape the distribution and abundance of plant life. This in turn could influence the ability of livestock to feed or even the local hydroclimate, through evapotranspiration feedbacks.

These results also remind us that ecosystems in Africa and beyond are more than just the sum of their species, and must be managed or altered with caution. 